\title{
Lo que el SARS-CoV-2 nos hurtó y lo que nos ilustró
}

\author{
What SARS-CoV-2 stole from us and what it taught us
}

Javier Lovo*

\section{INTRODUCCIÓN}

Los primeros vientos que anunciaban la plaga en China, nos parecían algo remoto, lejano a nuestro mundo, como si ocurriesen en Marte. ${ }^{1}$ Estábamos acostumbrados a escuchar de plagas que azotaban otros continentes, nos alarmamos cuando escuchamos que se desató un nuevo brote de Ébola, pero en el fondo sentíamos que ocurría en lugares alejados de nosotros, creemos muchas veces que esa distancia nos puede salvar. Tenemos nuestras propias pestes para contender con ellas todo el tiempo: el dengue, el chikungunya y el zika ya forman parte de nuestra cultura, siempre están allí amenazándonos, robándonos vida, pero nos hemos acostumbrado tanto a ellas, que sólo sentimos que son reales cuando nos despojan de un familiar; miramos de reojo al vecino que se enferma por los zancudos provenientes de nuestras casas. Pero de la forma que sea, existen métodos para controlar el zancudo, aunque para la enfermedad no exista un tratamiento específico o no se tenga una vacuna, sabemos dónde se tiene que golpear el árbol para que caigan las frutas.

Una nueva patología se desata, teniendo como origen aparente un mercado de la ciudad de Wuhan, en la provincia de Hubei en China, en los últimos días de diciembre del 2019. Para cuando se reporta de manera oficial a la OMS, ${ }^{2}$ los médicos y científicos chinos han llegado a brillantes conclusiones. Se trata de un nuevo virus, al que, incluso para ese momento, han logrado secuenciar genéticamente;

\footnotetext{
* Doctor en psicología (PhD) y doctor en medicina (MD). Residente de la especialidad en Medicina Familiar. Universidad de El Salvador-ISSS, San Salvador, El Salvador.
}

Correspondencia:

Javier Lovo

Correo electrónico: jvrlovo@gmail.com

Aceptado: 07-07-2020.

www.medigraphic.com/actamedica
Citar como: Lovo J. Lo que el SARS-CoV-2 nos hurtó y lo que nos ilustró. Acta Med. 2020; 18 (4): 438-440. https://dx.doi.org/10.35366/97280

sus principales manifestaciones clínicas son respiratorias y su transmisión es de persona a persona, por lo que medidas no farmacológicas como el aislamiento social parece ser lo único que la humanidad tiene en ese momento contra este nuevo virus.

El nuevo virus del grupo de los coronavirus, por su típica imagen al microscopio de coronas radiadas, comienza su expansión sin parangón en la historia universal, diseminándose punto por punto por el globo, aprovechándose de que el vehículo de transmisión es el mismo objeto de contagio: el ser humano. El mundo globalizado le sirve de acicate para que logre esparcirse con una rapidez que no se había predicho. El 11 de marzo de 2020 está marcado en la historia como el fatídico día en el que la OMS, con 118,300 casos confirmados por laboratorio y 4,292 muertes, declara oficialmente que se trata de una pandemia; ${ }^{3}$ a decir verdad, la primera pandemia universal.

En epidemiología se usan conceptos como pandemia y epidemia. El primero se trata de la concentración de nuevos casos en el tiempo; mientras que el segundo término se refiere a una enfermedad que se encuentra bastante extendida. ${ }^{4}$ El SARS-CoV-2 y la entidad que causa COVID-19, por sus siglas en inglés de enfermedad por Coronavirus 19, cumplió rápidamente estas definiciones, ya que al tratarse de una enfermedad nueva y de existir dos casos con iguales características con nexo geográfico o temporal, se cataloga como un brote epidémico. Asimismo, por su diseminación, pronto superó fronteras y alcanzó el grado de pandemia.

El título del presente ensayo parece presuntuoso, pero si analizamos a fondo la realidad que nos golpea, nos daremos cuenta de que el virus nos ha hurtado, además de la gran cantidad de pérdidas humanas que son irreparables, muchos elementos de nosotros, algunos de los cuales no podrán ser recuperados jamás.

\section{DESARROLLO}

Pero no te acerques tanto. Cuidado, no me tomes la mano, esta frase escrita por Benito Pérez Galdós, en su libro 
Episodios nacionales, ${ }^{5}$ parece reflejar una de las grandes cosas que el virus nos hurtó. Como seres humanos está en nuestra esencia socializar, formar comunidades, unirnos en un abrazo con otras personas, pero resulta que la forma del virus para transmitirse reside precisamente en esa necesidad humana de contacto. A falta de medicamentos efectivos, sólo quedan medidas no farmacológicas como el aislamiento social y la cuarentena; ${ }^{6}$ paradójicamente para sobrevivir, debemos abandonar nuestra necesidad de ser gregarios, la llamada es a mantenerse lejos de los demás, entre más lejos mejor, a aislarnos, a evitar en la medida de lo posible el contacto con otros humanos. El virus nos hurtó nuestra esencia social, para proteger a quienes queremos debemos estar lejos, a la vez nos ilustró sobre la importancia de la familia, aquellos que nunca permanecían en casa ahora han debido hacerlo, han debido conocer de primera mano la labores que se requieren para mantener un hogar funcionando. El virus ha obligado a que los padres pasen más tiempo con sus hijos, que los hermanos convivan de manera más extensa, nos ha alejado de nuestros vecinos y amigos, pero nos ha unido a nuestras familias de una forma sin precedentes.

Cuando se revisa la epidemiología de los afectados por el nuevo coronavirus, se encuentran categorías como pacientes con enfermedades crónicas, de edad avanzada o con obesidad, pero en ningún lugar aparece que afecte más a los estratos económicos más bajas, tampoco se menciona que afecte menos a los que cuentan con mayores recursos. " "Comunista" dirían algunos y vaya que el virus es el microorganismo más comunista que existe, no discrimina entre ricos y pobres, no le importa al Dios que dirijas tus plegarias por las noches, no le interesan tus preferencias sexuales, políticas o sociales. No discrimina a nadie en su camino de infección, el virus nos ha robado las ilusiones de que el poderío económico salvaría a algunos de infectarse, el SARS-CoV-2 ha cortado de tajo las ideas de que los más poderosos estarían a salvo, nos ha mostrado de una vez por todas que todos estamos en la misma tempestad, no en el mismo barco, porque algunos van en yates, otros en lanchas y algunos más a nado, pero todos sucumben a la misma tormenta. Nos ha ilustrado que podemos ser más solidarios con los otros, que nos podemos sacrificar para que otras personas vivan, ha reavivado el espíritu de la solidaridad humana.

Las economías se han visto devastadas; ${ }^{8}$ una recesión económica es muy probable, nuestro mundo se soporta en el dinero, pero con la llegada del nuevo virus nos hurta esa ilusión, ya que por primera vez caemos en cuenta, que es mucho más valiosa la salud y la vida, que no importa cuánto perdamos si con ello podemos mantener vivos a nuestros seres queridos. Nos ilustró sobre el valor que representa el personal de salud, que ahora contiende en primera línea con la pandemia, nos hizo reflexionar sobre la importancia de los hombres de ciencia para los enemigos biológicos que, como éste, seguramente surgirán en los años venideros. El SARS-CoV-2 nos mostró que el dinero y su poder son ilusiones, que algo tan minúsculo que se esconde a la vista es capaz de ponernos en jaque y desatar nuestros peores temores, nos robó la ilusión de que el dinero lo es todo y nos enseñó lo valioso que es la salud y la vida.

Con el embate del virus, los países han adoptado medidas estrictas de contención, de obligatorio cumplimiento para todos sus ciudadanos, algunas de estas estrategias han parecido draconianas, ${ }^{9}$ estas acciones —aunque necesarias - han permitido que el virus nos hurte esa sensación que previamente gozábamos, sobre ciertas libertades que los gobiernos podían, pero nunca habían usado en la escala actual. Con la actual pandemia, podemos ver en la realidad de los hechos los principios de vigilar y castigar, que con escenarios variopintos alrededor del mundo, nos muestra en mayor o menor medida el control que los estados pueden ejercer sobre las libertades individuales de sus ciudadanos. Los límites entre proteger la vida y salud de las mayorías, frente al acto punitivo de vigilar y castigar de los estados en muchos casos se han vuelto borrosos, ${ }^{10}$ ha sido necesaria la intervención de militares y las fuerzas del orden público por la magnitud de la pandemia, pero han sido algunos gobernantes quienes, de hecho con sus discursos, han logrado que se vuelva confusa la línea entre proteger y castigar.

En conjunto con la pandemia viral se ha expandido otra no menos extensa: la pandemia de la ideología; ${ }^{11}$ hasta dónde llegan los datos exactos de los alcances del virus, en dónde comienzan las noticias falsas que responden a la necesidad de desinformar, de infundir miedo. El virus nos ha mostrado que las luchas contra las grandes enfermedades no sólo recaen en las acciones de salud pública, sino también en el mundo de las ideas. Aún existen personas que creen que el virus no es real, por razones obvias no toman ninguna medida para protegerse, ni a ellos mismos ni a los demás. Lo más grave del asunto es que su ideología se vuelve viral, ya que cualquier persona con la que entablen una conversación será blanco de su infección ideológica, de la negación de la realidad, muchos serán absorbidos hacia su burbuja de irrealismo. Las redes sociales nos sirven para informarnos en cuestión de segundos de lo que ocurre en la realidad del mundo, colaboran para que la información se vuelva libre y escape a cualquier tipo de mordaza, pero existe una legión de personas que usan esta misma tecnología para desinformar, para crear caos. La pandemia de lo absurdo también está a la orden del día.

Es la misma pandemia del sin sentido que nos azota junto al virus, que hace que florezcan ideas realmente aterradoras en algunos segmentos de la población, como 
por ejemplo el desabastecimiento de papel higiénico, una cómica afrenta a la salud mental. ${ }^{11,12} \mathrm{~A}$ inicios de la pandemia hubo muchos que no se preocuparon si los agricultores podrían seguir produciendo los alimentos necesarios para sostener a la población en los duros momentos que vendrían, su principal preocupación fue que los supermercados se quedaran si papel higiénico, todos fuimos testigos de los carritos llenos de rollos dejando estanterías vacías, la preocupación por cosas banales que el consumismo nos ha fomentado, nos lleva a que soslayemos la mirada sobre las cosas que realmente deberían inquietarnos. Pudimos conocer por fin que la labor titánica de los agricultores, los siempre mal pagados, los más trabajados y menos valorados de nuestras sociedades, son los mismos que mantienen nuestros estómagos saciados, sorprendente pero real.

Lo más importante que nos ha mostrado el SARS-CoV-2 ha sido el valor de la vida, algunos la han estimado en términos económicos, cuánto representan las pérdidas humanas, ${ }^{13}$ pero más allá de esto, el virus nos ha mostrado lo valioso que es poseer vida, nos ha señalado que por muy difícil que sean los escenarios de vida de las personas, mientras se pueda respirar se puede seguir, existe la posibilidad de ser felices, pero todo acaba cuando la vida se pierde. Todo se torna insignificante frente al gran valor que la vida y la salud representan para la humanidad.

\section{CONCLUSIÓN}

Algunos venden la idea de que el fin de la pandemia habrá de llegar, argumentan que todo tiene un génesis y también un ocaso, si esto es veraz o una más de nuestras ilusiones, es algo que sólo el juez llamado tiempo puede revelarnos. Lo cierto es que algunos ponen su esperanza en el desarrollo de una potencial vacuna que sea la cura de todos los males arrastrados por el SARS-CoV-2, y pese a que muchas personas de ciencia en el mundo dedican sus energías a esta difícil faena, ${ }^{14}$ debemos reconocer que el desarrollo de una vacuna conlleva múltiples desafíos, que en el pasado fueron tan poderosos como para frenar el avance de importantes vacunas. La ilusión de regreso a la normalidad, al menos en corto plazo, no nos debe cegar, debemos saber que no es el virus que nos terminara matando si no aprendemos a contender con él, será el individualismo y el miedo lo que favorecerá al virus para que nos arranque miles de vidas más de las que ya se llevó.

Ha llegado el momento de reconocer que somos gotas de agua en el inmenso mar que representa la humanidad, pero que si una sola gota de agua se contamina, todo el enorme océano estará en riesgo, no somos islas, sino eslabones de la misma cadena. Debemos aprender a convivir con las medidas de prevención necesarias para enfrentar al virus, así como ser solidarios los unos con los otros, quizá solo así, las sociedades salgan fortalecidas de esta guerra contra un enemigo invisible que, sin embargo, está destruyéndonos.

\section{REFERENCIAS}

1. Rourke EJ. Waiting. N Engl J Med. 2020. Available in: https://www. nejm.org/doi/full/10.1056/NEJMp2007073.

2. WHO. Novel coronavirus - China. [Internet]. (12 de enero, 2020). [Citado 15 mayo 2020] Available in: https://www.who.int/csr/don/12january-2020-novel-coronavirus-china/en/.

3. World Health Organization (WHO). Coronavirus disease 2019 (COVID-19) Situation Report - 51. [Internet]. 2020 [Cited 15 May 2020] Available in: https://www.who.int/docs/default-source/coronaviruse/ situation-reports/20200311-sitrep-51-covid-19.pdf?sfvrsn=1 ba62e57_10.

4. Fletcher RH, Fletcher SW, Fletcher GS. Epidemiología clínica. Barcelona: Wolters Kluwer/Lippincott Williams \& WIlkins, 2016.

5. Pérez GB. Episodios Nacionales. Tomo I, Madrid. Aguilar. 1995.

6. Wilder-Smith A, Freedman DO. Isolation, quarantine, social distancing and community containment: pivotal role for old-style public health measures in the novel coronavirus (2019-nCoV) outbreak. J Travel Med. 2020; 27 (2): taaa020.

7. Siordia JA Jr. Epidemiology and clinical features of COVID-19: a review of current literature. J Clin Virol. 2020; 127: 104357.

8. Ibarra D. La economía mundial y sus vericuetos (incluido el coronavirus). Economía UNAM. 2020; 17 (50): 3-26.

9. Parmet WE, Sinha MS. COVID-19 - the law and limits of quarantine. N Engl J Med. 2020; 382 (15): e28-e28.

10. López-García G. Vigilar y castigar: el papel de militares, policías y guardias civiles en la comunicación de la crisis del COVID-19 en España. El profesional de la información (EPI). 2020; 29 (3).

11. Žižek S. Pandemic! COVID-19 shakes the world. New York: Polity Press. OR Books. 2020.

12. Quezada-Schol V. Miedo y psicopatología la amenaza que oculta el COVID-19. Cuadernos de Neuropsicología/Panamerican Journal of Neuropsychology.2020; 14 (1): 19-23.

13. Kirigia JM, Muthuri RNDK. The fiscal value of human lives lost from coronavirus disease (COVID-19) in China. Version 2. BMC Res Notes. 2020; 13 (1): 198.

14. Lurie N, Saville M, Hatchett R, Halton J. Developing COVID-19 vaccines at pandemic speed. N Engl J Med. 2020; 382: 1969-1973. doi: 10.1056/NEJMp2005630. 